\title{
Clinical Course of Ulcerative Colitis Associated with an Age at Diagnosis: A Recent Japanese Database Survey
}

\author{
Yosuke Shimodaira, ${ }^{1}$ Kenta Watanabe ${ }^{1}$ and Katsunori Iijima ${ }^{1}$ \\ ${ }^{1}$ Department of Gastroenterology and Neurology, Akita University Graduate School of Medicine, Akita, Akita \\ Japan
}

The onset age of ulcerative colitis has been increasing in several countries. Furthermore, the number of elderly patients with ulcerative colitis has been increasing in an aging society. We investigated the incidence of ulcerative colitis patients in Japan using a large-scale health insurance claims database to survey the ulcerative colitis incidence ratio and the clinical characteristics in late-onset ulcerative colitis patients. Newly diagnosed 2,791 ulcerative colitis between 2015 and 2018 was investigated. Medical treatment within 12 months of diagnosis was analyzed among 0-19, 20-39, 40-59 and 60-75 age groups. The mean age at diagnosis was 40.3 years (SD: 12.9), and the incidence ratio peaked in the 40's. Most of patients received 5-aminocylitic acid (91.7\%), a subset of patients received prednisolone (20.1\%), and a small number of patients took immunomodulator (6.8\%), cytapheresis (3.3\%), anti-TNF $\alpha$ therapy $(4.3 \%)$, and colectomy $(1.0 \%)$ within 12 months after diagnosis. All treatments except colectomy were most frequent in the 0-19 age group; however, colectomy was most frequent in 60-75 age group. The clinical course of ulcerative colitis that developed in adults did not differ significantly in terms of medical treatment within 12 months from the onset; meanwhile, the surgery rate was high in elderly patients. It is necessary to pay close attention to future trends regarding the aging of the onset age and the treatment, especially for late-onset ulcerative colitis patients.

Keywords: Japanese database; late onset; onset age; surgery; ulcerative colitis

Tohoku J. Exp. Med., 2021 September, 255 (1), 33-39.

\section{Introduction}

Ulcerative colitis causes chronic colonic mucosal inflammation (Ungaro et al. 2017). The pathogenesis of ulcerative colitis is not fully understood because it is related to multiple complex factors such as genetic predisposition and environmental factors associated with intestinal immune disorders. Ulcerative colitis patients experience chronic course of disease repeating the relapse and remission stages, resulting in the occurrence of colorectal cancer (Jess et al. 2012), and no curable treatment is available for ulcerative colitis. In order to unmask the pathophysiology and improve the treatment, ulcerative colitis was designated as an intractable disease, and the study group was launched by the Ministry of Health and Welfare in 1973 in Japan.

Accumulating data have shown that susceptible age is late adolescence to young adults, mostly in the 20's and 30's (Shivananda et al. 1996; Loftus et al. 2000; Molinié et al. 2004; Matsuoka et al. 2018). The prevalence of ulcerative colitis is high (286 cases per 100,000 persons in the Olmsted County, USA and 505 cases per 100,000 persons in Southeast, Norway) in western countries and also has been increasing globally (Kaplan and $\mathrm{Ng}$ 2017; Ng et al. 2017), including in Japan (172.9 cases per 100,000 persons) (Murakami et al. 2019). In the latest registry data that was accumulated until 2012 in Japan, 30's was the most susceptible age for onset of ulcerative colitis which was higher than that previously observed. Considering that the susceptible age of incidence ratio has been gradually increasing, the incidence of ulcerative colitis patients is increasing in elderly individuals. There has been an issue of population aging, the number of persons aged 65 or over has increased from $17.4 \%$ in 2000 to $26.6 \%$ in 2015 in Japan (Statistics Bureau of Japan 2020).

Aging societies, such as Japan, will encounter many health issues with late-onset ulcerative colitis. Late-onset ulcerative colitis patients over 65 years of age have relatively decreased organ function, increased comorbidities, and sometimes take multiple drugs; thus, elder ulcerative colitis patients are compromised and addressed with higher mortality with colectomy (Nicholls et al. 2010; Kaplan et al. 2011). There have been several controversial reports on

Received March 25, 2021; revised and accepted June 7, 2021. Published online September 11, 2021; doi: 10.1620/tjem.255.33.

Correspondence: Yosuke Shimodaira, Department of Gastroenterology and Neurology, Akita University Graduate School of Medicine,

1-1-1 Hondo, Akita, Akita 0108543, Japan.

e-mail: yosuke.shimodaira@med.akita-u.ac.jp

(C)2021 Tohoku University Medical Press. This is an open-access article distributed under the terms of the Creative Commons Attribution-NonCommercial-NoDerivatives 4.0 International License (CC-BY-NC-ND 4.0). Anyone may download, reuse, copy, reprint, or distribute the article without modifications or adaptations for non-profit purposes if they cite the original authors and source properly.

https://creativecommons.org/licenses/by-nc-nd/4.0/ 
the clinical course and medical treatment of late-onset ulcerative colitis. Late-onset ulcerative colitis was benign compared to early-onset (Lakatos et al. 2011), and ulcerative colitis-related medical care was required less frequently (Nguyen et al. 2015). In addition, a frequency of immunomodulator and infliximab treatment in the onset at ages 50 and over compared to that at ages 18-30 years were similar, and steroid-free remissions one year after the diagnosis in these cohorts were comparable (Ha et al. 2010). On the other hand, disease activities and biological markers were elevated in late-onset ulcerative colitis compared to early-onset ulcerative colitis (Komoto et al. 2018), and lateonset ulcerative colitis patients were more likely to undergo surgery within 12 months post diagnosis (Ananthakrishnan et al. 2016). However, the conclusion was still unclear regarding the clinical course according to the onset age. More evidence is still needed regarding increased incidence of late-onset ulcerative colitis.

Thus, we investigated the incidence of ulcerative colitis patients in Japan using a recent administrative largescale database to survey the ulcerative colitis incidence ratio and the clinical characteristics in late-onset ulcerative colitis patients.

\section{Materials and Methods}

\section{Data sources}

Population-based administrative data were available from the Japan Medical Data Center (JMDC) health insurance claims database. The JMDC database contains medical and prescription claims with diagnoses coded using the $10^{\text {th }}$ revision of the International Statistical Classification of Diseases and Related Health Problems (ICD-10) classification and Japanese standard disease code, drug prescription information coded using the Anatomical Therapeutic Chemical Classification System (ATC) including generic drugs, and clinical procedures defined with Japanese standardized procedure code. The database included either in the hospitalization and outpatient claims data from the Japan Health Insurance Association. The database includes individuals belonging to the Japan Health Insurance Association and most of people included were workers and their dependent families under 75 years old. Demographic information including sex and age was also obtained from the database. Approximately 7 million people who had received a diagnosis and prescription from 2005 to 2019 were accumulated in the database. Approximately 7 million people who had received a diagnosis and prescription from 2005 to 2019 were accumulated in the database. In the database, the diagnosis, prescription, and clinical procedures in any hospital or clinic were available with a unique identification number for each individual; however, personally identifiable information was unavailable.

\section{Study population and definition}

Patients with a newly diagnosed ulcerative colitis were enrolled using the ICD-10 classification, K-51. Subjects were identified in the JMDC database from January 2015 to December 2018. Eligibility of new ulcerative colitis diagnosis was ascertained by following up the diagnosis for 1 year without change of diagnosis code and no ulcerative colitis diagnosis code for 24 months prior to the first diagnosis code occurred. Patients who had been diagnosed or suspected with ulcerative colitis before were excluded. The date of ulcerative colitis onset was defined with the first documentation of the ICD-10 diagnostic code. Therapeutic information was collected as follows; 5-aminocylitic acid (either oral or topical forms of mesalazine and salazosulfapyridine); systemic glucocorticoids (either intravenous injection or oral prednisolone); immunomodulators (azathioprine and 6-mercaptopurine); cytapheresis (leukocytapheresis and granulocyte and monocyte adsorption apheresis); anti-tumor necrosis factor $\alpha$ (TNF $\alpha$ ) (infliximab, adalimumab, golimumab, and infliximab biosimilar); and colectomy (surgery with intestinal resection).

\section{Objectives and evaluation}

The primary objective of this study was to investigate the age at the onset of ulcerative colitis. The incidence ratio, represented as the number per 100,000 population, was calculated according to the number of population in each age group. We investigated the treatment with 5-aminocylitic acid, immunomodulators, cytapheresis, systemic glucocorticoids, anti-TNF $\alpha$, and colectomy within 12 months of the diagnosis according to the onset age. Hospitalization at onset was defined as the event on the month or next month of the diagnosed day.

\section{Ethical considerations}

As the data provided by the JMDC were anonymous without any link to individual persons, approval by the institutional ethics committee and informed consent was not required in accordance with the ethical guidelines for epidemiological research issued by the Japanese Ministry of Health, Labour, and Welfare.

\section{Statistical analysis}

The patients were divided into four groups according to age as follows: $0-19,20-39,40-59$, and 60-75. Statistical differences between age classes were analyzed by Fisher's exact test because all clinical variables were categorical. Bonferroni correction was performed as a post-hoc analysis. All analyses were conducted using EZR software (Saitama Medical Center, Jichi Medical University, Saitama, Japan) (Kanda 2013) and P-values $<0.05$ were considered as a significant difference.

\section{Results}

The demographic characteristics and medication of the newly diagnosed 2,420 ulcerative colitis subjects included in this study are shown in Table 1 . The mean age at diagnosis was 40.3 years (SD: 12.9). At onset, $14.1 \%$ of patients were hospitalized. Most of patients received 
Table 1. Cohort demographic characteristics and medical treatment.

\begin{tabular}{lc}
\hline & Ulcerative colitis \\
\hline Overall, number & 2,420 \\
Male, n (\%) & $1,596(66.0 \%)$ \\
At diagnosis & \\
Age, mean \pm SD (years) & $40.3 \pm 12.9$ \\
Age, 1st, 2nd, 3rd quartile & $32,41,50$ \\
Hospitalization, n (\%) & $342(14.1 \%)$ \\
Medical treatment & \\
5-Aminocylitic acid, n (\%) & $2,219(91.7 \%)$ \\
Systemic glucocorticoids, n (\%) & $487(20.1 \%)$ \\
Immunomodulators, n (\%) & $165(6.8 \%)$ \\
Cytapheresis, n (\%) & $81(3.3 \%)$ \\
Anti-TNFa, n (\%) & $105(4.3 \%)$ \\
Colectomy, n (\%) & $24(1.0 \%)$ \\
\hline
\end{tabular}

Anti-TNFa, anti-tumor necrosis factor a; SD, standard deviation.

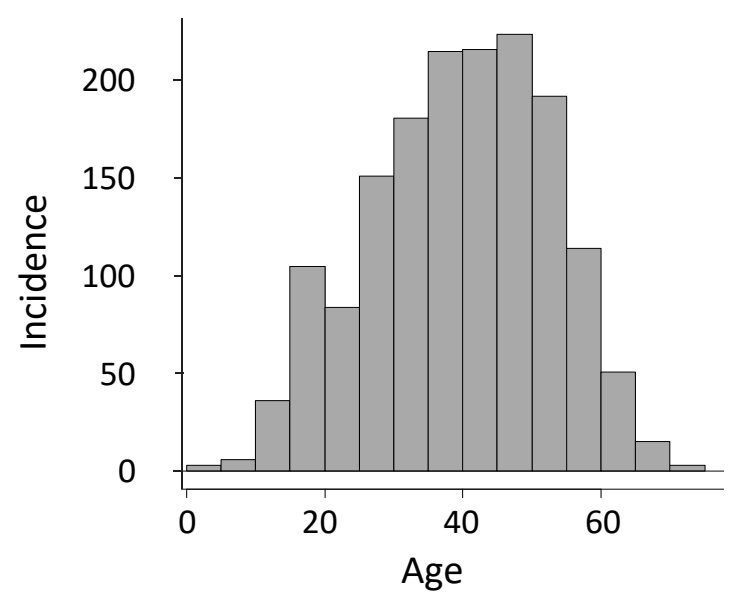

5-aminocylitic acid (91.7\%), a subset of patients received glucocorticoids $(20.1 \%)$, and a small number of patients took immunomodulators $(6.8 \%)$, cytapheresis $(3.3 \%)$, anti$\mathrm{TNF} \alpha$ therapy $(4.3 \%)$, and colectomy $(1.0 \%)$ within 12 months after diagnosis. The age distribution at diagnosis of ulcerative colitis is shown in Fig. 1. Most patients presented with ulcerative colitis in their 40's, followed by those in 30's and 50's. The incidence ratio produced by the incidence number as per the number of the population was also the highest in the 40's and broadly developed in all age sets (Fig. 2). Then, the age distribution of the population in the database was confirmed. The database, comprising of 0 to 75 years old population, showed peaks at 0 to 4 years of age and the 20's (Fig. 3a). To compare the demographics of Japan on March 1, 2020 (Fig. 3b), we included a relatively younger population from the JMDC database.

Thereafter, the treatment according to the onset age was investigated. We divided the patients into four groups

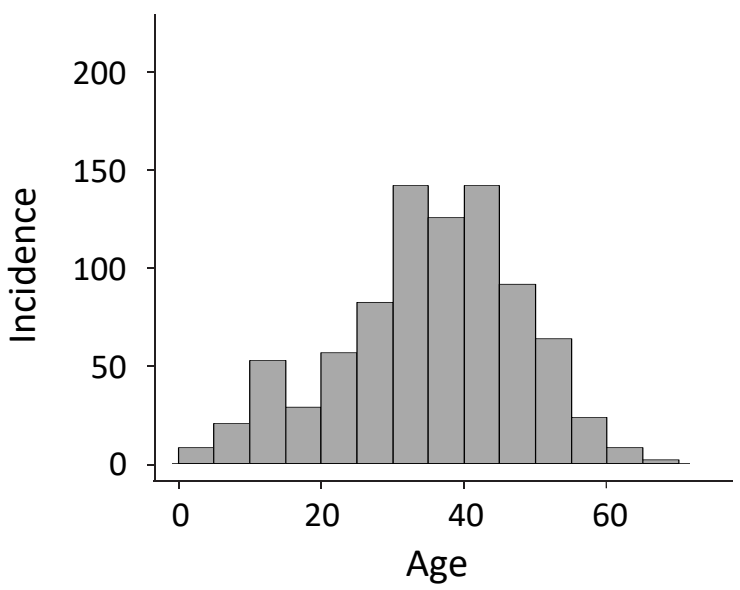

Fig. 1. The number of newly diagnosed ulcerative colitis cases in males (left) and females (right) in Japan Medical Data Center (JMDC) database in 2015-2018.

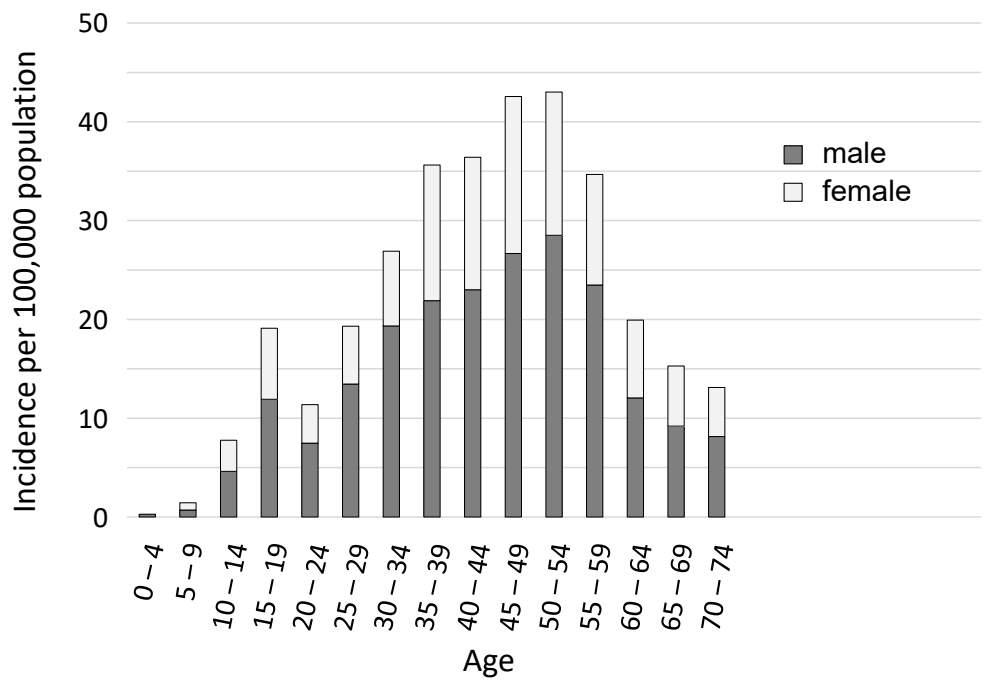

Fig. 2. Ulcerative colitis diagnosis per 100,000 population in Japan Medical Data Center (JMDC) database between 2015 and 2018 on each age set. 

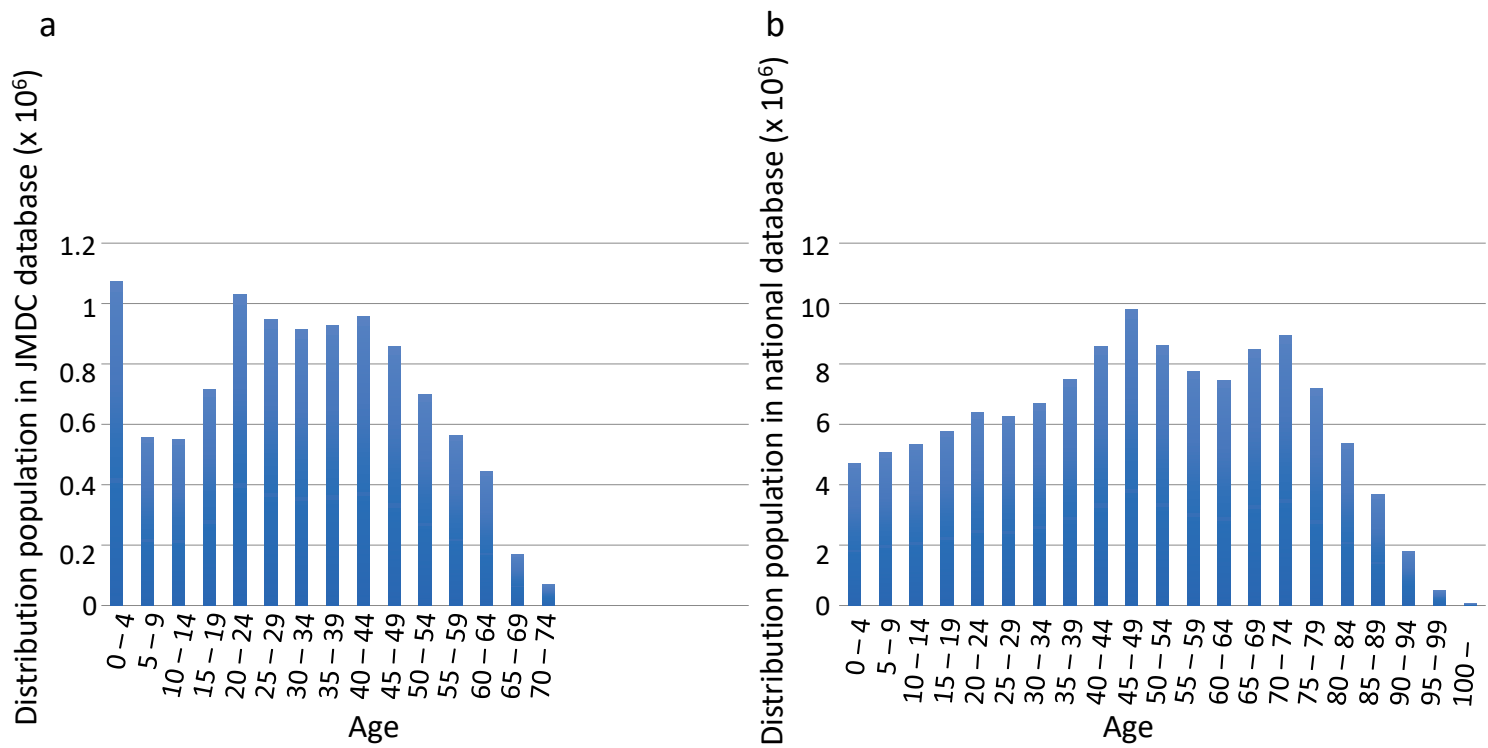

Fig. 3. Distribution population in Japan.

Distribution population in Japan Medical Data Center (JMDC) database was graphed on each age set.

(b) Distribution population in the demographic of Japan on March 1st, 2020 on each age set.

Table 2. Hospitalization at ulcerative colitis (UC) onset and medical treatment within 12 months in each age set.

\begin{tabular}{|c|c|c|c|c|c|c|}
\hline & \multirow[b]{2}{*}{ UC all } & \multicolumn{4}{|c|}{ Age (years) } & \multirow[b]{2}{*}{$P$ value } \\
\hline & & $0-19 ; 1^{\text {st }}$ group & $20-39 ; 2^{\text {nd }}$ group & $40-59 ; 3^{\text {rd }}$ group & $60-75 ; 4^{\text {th }}$ group & \\
\hline Number & 2,420 & 196 & 888 & 1,210 & 126 & \\
\hline Hospitalization, n (\%) & $342(14.1 \%)$ & $64(32.7 \%)$ & $111(12.5 \%)$ & $143(11.8 \%)$ & $24(19.0 \%)$ & $1.14 \times 10^{-11 \mathrm{a}}$ \\
\hline 5-Aminocylitic acid, n (\%) & $2,219(91.7 \%)$ & $186(94.9 \%)$ & $842(94.8 \%)$ & $1,083(89.5 \%)$ & $108(85.7 \%)$ & $3.23 \times 10^{-6 b}$ \\
\hline Systemic glucocorticoids, n (\%) & $487(20.1 \%)$ & $85(43.4 \%)$ & $168(18.9 \%)$ & $207(17.1 \%)$ & $27(21.4 \%)$ & $1.44 \times 10^{-13 \mathrm{a}}$ \\
\hline Immunomodulators, n (\%) & $165(6.8 \%)$ & $35(17.9 \%)$ & $58(6.5 \%)$ & $63(5.2 \%)$ & $9(7.1 \%)$ & $2.55 \times 10^{-7} \mathrm{a}$ \\
\hline Cytapheresis, n (\%) & $81(3.3 \%)$ & $18(9.2 \%)$ & $28(3.2 \%)$ & $30(2.5 \%)$ & $5(4.0 \%)$ & $2.71 \times 10^{-4 c}$ \\
\hline Anti-TNF $\alpha, \mathrm{n}(\%)$ & $105(4.3 \%)$ & $26(13.2 \%)$ & $40(4.5 \%)$ & $34(2.8 \%)$ & $5(4.0 \%)$ & $1.85 \times 10^{-7 \mathrm{a}}$ \\
\hline Colectomy, n (\%) & $24(1.0 \%)$ & $3(1.5 \%)$ & $4(0.5 \%)$ & $13(1.1 \%)$ & $4(3.2 \%)$ & $6.4 \times 10^{-2 \mathrm{~d}}$ \\
\hline
\end{tabular}

Anti-TNF $\alpha$, anti-tumor necrosis factor $\alpha$.

${ }^{\text {a }} 1^{\text {st }}>2^{\text {nd }}, 3^{\text {rd }}$, and $4^{\text {th }}$

b $1^{\text {st }}$ and $2^{\text {nd }}>4^{\text {th }}, 2^{\text {nd }}>3^{\text {rd }}$

c $1^{\text {st }}>2^{\text {nd }}$ and $3^{\text {rd }}$

d $4^{\text {th }}>2^{\text {nd }}$

according to age set: under 19 years old ( $1^{\text {st }}$ group), 20 to 39 years old ( $2^{\text {nd }}$ group), 40 to 59 years old ( $3^{\text {rd }}$ group), and 60-75 years old ( $4^{\text {th }}$ group). The percentages of hospitalization, systemic glucocorticoids therapy, immunomodulators, cytapheresis, and anti-TNF $\alpha$ therapy in all subjects were $14.1 \%, 20.1 \%, 6.8 \%, 3.3 \%$, and $4.3 \%$, respectively, and $32.7 \%, 43.4 \%, 17.9 \%, 9.2 \%$, and $13.2 \%$, respectively in $1^{\text {st }}$ group, which might reflect more severe clinical phenotype in ulcerative colitis under 19 years of age (Turner et al. 2008; Van Limbergen et al. 2008). While the percentage of colectomy was comparable among all subjects $(1.0 \%), 1^{\text {st }}$ group $(1.5 \%), 2^{\text {nd }}$ group $(0.5 \%), 3^{\text {rd }}$ group $(1.1 \%)$, and $4^{\text {th }}$ group $(3.2 \%)(\mathrm{P}=0.064)$, those aged $60-75$ underwent colectomy more than those aged 20-39 $(\mathrm{P}=0.0142)$ in adult setting excluding $1^{\text {st }}$ group and substantially increased with age (Table 2).

\section{Discussion}

In this study, the characteristics and treatment of newly diagnosed ulcerative colitis between 2015 and 2018 were investigated using a large-scale Japanese claims database. The database has been accumulating the data of individuals who belong the insurance since 2005. The large-scale database including approximately 7 million people has been recently analyzed for a real world prescription and an epidemiological research (Sato et al. 2019; Kobayashi et al. 2020; Matsuoka et al. 2021). The main focus of this study was the age distribution at ulcerative colitis diagnosis and evaluating the treatment of late-onset ulcerative colitis patients. 
In this study, new incidence of ulcerative colitis was most frequent in the 40's and incidence rate per population was the highest with 79 patients (the number in 40-44 years of age and 45-49 years of age in Fig. 2) per 100,000 people in the 40's. There have been several reports showing increasing late-onset ulcerative colitis. A population-based study in Hungary demonstrated that the adjusted elderly onset ulcerative colitis was 1.09 in 1977-1981 and 10.8 in 2002-2007 (Lakatos et al. 2011), and Hong Kong registry data showed that the average onset age had risen with 33.64 before 1990 to 46.58 in 2010 (Shi et al. 2016). In a Dutch cohort, the incidence rate of ulcerative colitis over the age of 60 was 9.20 per 100,000 in 1991, which increased to 17.43 per 100,000 in 2010 (Jeuring et al. 2016). Although the source used in this study was different from other studies and identification of ulcerative colitis was due to the disease code, along with the current data that included newly diagnosed ulcerative colitis patients only in 20152018, the age of onset was middle in Japan.

Of note, the newly diagnosed patients with Crohn's disease who were also examined using the same database showed a peak in the teens to 20's which has been consistent depending on the era and the region (Fig. 4) (Lakatos et al. 2011; Jeuring et al. 2016; Hwang et al. 2017). Especially for ulcerative colitis rather than Crohn's disease, alteration in the intestinal microenvironment due to different hygienic standards and westernizing lifestyle and diet may contribute to the development of disease. Importantly, cessation of smoking has been revealed as a risk factor for the development of ulcerative colitis. Increasing ex-smokers in Japan for a couple of decades would affect onset of ulcerative colitis. Indeed, a retrospective cohort study according to the ulcerative colitis onset age in South Korea also showed that ex-smokers were higher in population over 60 years old compared to those under 60 years of age (Song et al. 2018).

There may be a lag between the time when the illness develops and when it is diagnosed; this difference may be large, especially if the severity is mild. Despite of a recall bias, questionnaire survey data can serve as a reference for the time of disease development. Takahashi et al. (2014) showed that the peak of ulcerative colitis onset was 20's (mean: 34.7 years old); however, it shows that the mean of the cases after 2001 increased from 30.8 years to 36.9 years compared to the cases before 2000. Furthermore, smoking cessation has been pointed out as a risk of developing the disease over 50 years of age in this cohort.

Next, the treatment by age set was examined and it showed that patients younger than 20 years of age required increased hospitalization, glucocorticoids, and anti-TNF $\alpha$ therapy, suggesting that ulcerative colitis with this onset age may be more severe than that with late onset. The younger population under 20 years of age, which may include those with monogenic inflammatory bowel disease, often experience intractable and severe phenotypes. Kalkan et al. (2013) reported that those with early-onset ulcerative colitis under age 17 needed more steroids and colectomy than adult-onset and late-onset ulcerative colitis. Since the treatments in the pediatric field and in adults were different, the treatment in an adult setting was also investigated. In adult onset, there was no difference in hospitalization and treatment contents by age group in this study. Previous report showed no difference in the therapy needed between lateand early-onset ulcerative colitis (Shi et al. 2016). Another report showed less frequent use of immunomodulator and biologics in late-onset ulcerative colitis (Ananthakrishnan et al. 2016). However, older individuals who often take multiple drugs should be closely monitored, as the other drugs can interact with ulcerative colitis drugs leading to unfavorable events (Stallmach et al. 2011). In addition, a special caution is required with adverse events with individual ulcerative colitis drugs related to the organ disorders, such as renal function with 5-aminocylitic acid; osteoporosis, infection, and increasing blood glucose with glucocorticoids; infection and heart failure with anti-TNF $\alpha$ (Gisbert et al. 2007; Toruner et al. 2008; Cottone et al. 2011; Taleban

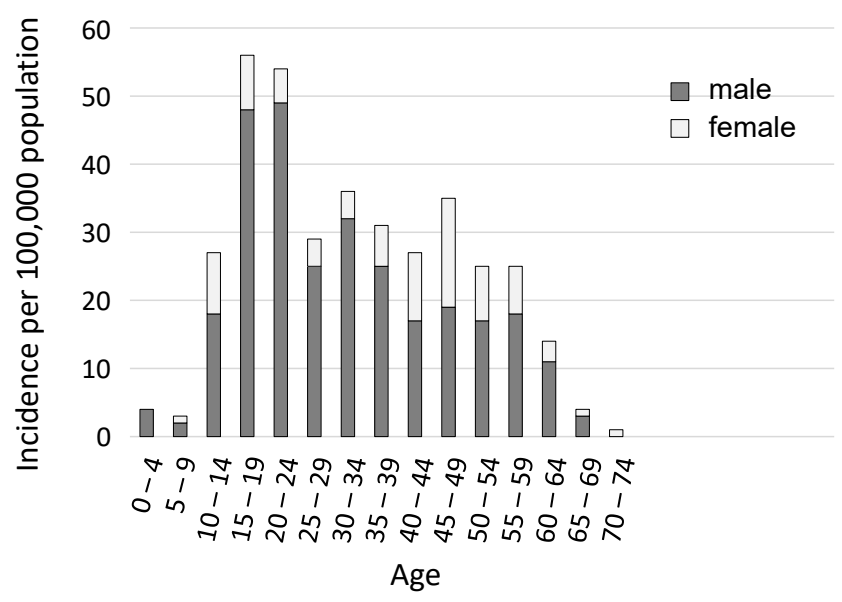

Fig. 4. Crohn's disease diagnosis per 100,000 population between 2015 and 2018 in Japan Medical Data Center (JMDC) database on each age set. 
et al. 2015). On the other hand, although the analyzed patient number was small, the present study showed that the elderly-onset population underwent colectomy at a higher percentage than the younger-onset population. Ananthakrishnan et al. (2016) reported that patients with late-onset ulcerative colitis underwent surgery more often than those with early-onset ulcerative colitis in a systematic review (Komoto et al. 2018). This observation implies that older individuals had relatively less tolerability due to their underlying disease and decreased multi-organ function. Prospective study with a large number of patients will be still needed to address the treatment strategy for late-onset ulcerative colitis.

There were some limitations in this study due to the retrospective and database nature of the study. First, the database was not available with information that was necessary for ulcerative colitis diagnosis, such as endoscopy, pathology, clinical course, severity, and environmental factors such as smoking habit. Thus, the diagnosis of ulcerative colitis in this study was based on the disease code. In the present study, to exclude other enteritis, the new onset of ulcerative colitis was defined as the absence of the diagnosis code for 24 months prior to the first diagnosis and without changing the diagnosis for 12 months. It was also confirmed that almost all cases were treated with ulcerative colitis treatment such as 5 -aminocylitic acid. Furthermore, no information was available in more than 24 months before the diagnosis. Second, this database did not include elderly individuals over 75 years of age, so it was not possible to examine the characteristics of the onset of the disease in individuals above 75 years of age. Although the data of the super-elderly were unavailable, the analysis by age groups showed that the surgery rate increased as the age group increased. The surgery rate was expected to be even higher in the super-elderly, but this is still considered to be an issue for future investigations. In addition, the age of onset reported, including that in this study, reflected the age at the time of diagnosis and may be slightly different from the age of actual onset of developing disease. Two-year period before the diagnosis was confirmed without ulcerative colitis diagnosis code, however, the data was not available more than 2 years before the diagnosis. Ulcerative colitis could occasionally flare after a long quiescent period. In addition, it should be considered that the age of diagnosis was affected by urban areas with easy access to hospitals, insurance systems, number of specialists in the region, etc.

In conclusion, the diagnosed age of ulcerative colitis in Japan is middle in a recent Japanese large-scale health insurance claims database. The clinical course of ulcerative colitis developed in adults does not differ significantly in the medical treatment within 12 months from the onset; meanwhile, the surgery rate is high in elderly patients. As it is expected that the number of late-onset ulcerative colitis will continue to increase in the future, it will be necessary to consider the treatment carefully. It is necessary to con- tinue to pay close attention to future trends regarding the aging of the onset age and the treatment, especially for lateonset ulcerative colitis patients.

\section{Author Contributions}

Conceptualization: Yosuke Shimodaira; Methodology: Yosuke Shimodaira; Formal analysis and investigation: Yosuke Shimodaira, Kenta Watanabe; Writing - original draft preparation: Yosuke Shimodaira; Writing - review and editing: Kenta Watanabe, Katsunori Iijima. All authors read and approved the final manuscript.

\section{Conflict of Interest}

The authors declare no conflict of interest.

\section{References}

Ananthakrishnan, A.N., Shi, H.Y., Tang, W., Law, C.C., Sung, J.J., Chan, F.K. \& Ng, S.C. (2016) Systematic review and metaanalysis: phenotype and clinical outcomes of older-onset inflammatory bowel disease. J. Crohns Colitis, 10, 12241236.

Cottone, M., Kohn, A., Daperno, M., Armuzzi, A., Guidi, L., D’Inca, R., Bossa, F., Angelucci, E., Biancone, L., Gionchetti, P., Ardizzone, S., Papi, C., Fries, W., Danese, S., Riegler, G., et al. (2011) Advanced age is an independent risk factor for severe infections and mortality in patients given anti-tumor necrosis factor therapy for inflammatory bowel disease. Clin. Gastroenterol. Hepatol., 9, 30-35.

Gisbert, J.P., Gonzalez-Lama, Y. \& Mate, J. (2007) 5-Aminosalicylates and renal function in inflammatory bowel disease: a systematic review. Inflamm. Bowel Dis., 13, 629-638.

Ha, C.Y., Newberry, R.D., Stone, C.D. \& Ciorba, M.A. (2010) Patients with late-adult-onset ulcerative colitis have better outcomes than those with early onset disease. Clin. Gastroenterol. Hepatol., 8, 682-687 e681.

Hwang, S.W., Kim, J.H., Im, J.P., Ye, B.D., Koo, H.S., Huh, K.C., Cheon, J.H., Kim, Y.S., Kim, Y.H., Han, D.S., Kim, W.H. \& Kim, J.S.; Crohn's disease clinical network and cohort (CONNECT) study (2017) Influence of age at diagnosis on the clinical characteristics of Crohn's disease in Korea: results from the CONNECT study. J. Gastroenterol. Hepatol., 32, 1716-1722.

Jess, T., Rungoe, C. \& Peyrin-Biroulet, L. (2012) Risk of colorectal cancer in patients with ulcerative colitis: a metaanalysis of population-based cohort studies. Clin. Gastroenterol. Hepatol., 10, 639-645.

Jeuring, S.F., van den Heuvel, T.R., Zeegers, M.P., Hameeteman, W.H., Romberg-Camps, M.J., Oostenbrug, L.E., Masclee, A.A., Jonkers, D.M. \& Pierik, M.J. (2016) Epidemiology and long-term outcome of inflammatory bowel disease diagnosed at elderly age-an increasing distinct entity? Inflamm. Bowel Dis., 22, 1425-1434.

Kalkan, I.H., Dagli, U., Oztas, E., Tunc, B. \& Ulker, A. (2013) Comparison of demographic and clinical characteristics of patients with early vs. adult vs. late onset ulcerative colitis. Eur. J. Intern. Med., 24, 273-277.

Kanda, Y. (2013) Investigation of the freely available easy-to-use software 'EZR' for medical statistics. Bone Marrow Transplant., 48, 452-458.

Kaplan, G.G., Hubbard, J., Panaccione, R., Shaheen, A.A., Quan, H., Nguyen, G.C., Dixon, E., Ghosh, S. \& Myers, R.P. (2011) Risk of comorbidities on postoperative outcomes in patients with inflammatory bowel disease. Arch. Surg., 146, 959-964.

Kaplan, G.G. \& Ng, S.C. (2017) Understanding and preventing the global increase of inflammatory bowel disease. Gastroen- 
terology, 152, 313-321 e312.

Kobayashi, T., Udagawa, E., Uda, A., Hibi, T. \& Hisamatsu, T. (2020) Impact of immunomodulator use on treatment persistence in patients with ulcerative colitis: a claims database analysis. J. Gastroenterol. Hepatol., 35, 225-232.

Komoto, S., Higashiyama, M., Watanabe, C., Suzuki, Y., Watanabe, M., Hibi, T., Takebayashi, T., Asakura, K., Nishiwaki, Y., Miura, S. \& Hokari, R. (2018) Clinical differences between elderly-onset ulcerative colitis and non-elderly-onset ulcerative colitis: a nationwide survey data in Japan. J. Gastroenterol. Hepatol., 33, 1839-1843.

Lakatos, P.L., David, G., Pandur, T., Erdelyi, Z., Mester, G., Balogh, M., Szipocs, I., Molnar, C., Komaromi, E., Kiss, L.S. \& Lakatos, L. (2011) IBD in the elderly population: results from a population-based study in Western Hungary, 19772008. J. Crohns Colitis, 5, 5-13.

Loftus, E.V. Jr., Silverstein, M.D., Sandborn, W.J., Tremaine, W.J., Harmsen, W.S. \& Zinsmeister, A.R. (2000) Ulcerative colitis in Olmsted County, Minnesota, 1940-1993: incidence, prevalence, and survival. Gut, 46, 336-343.

Matsuoka, K., Igarashi, A., Sato, N., Isono, Y., Gouda, M., Iwasaki, K., Shoji, A. \& Hisamatsu, T. (2021) Trends in corticosteroid prescriptions for ulcerative colitis and factors associated with long-term corticosteroid use: analysis using Japanese claims data from 2006 to 2016. J. Crohns Colitis, 15, 358-366.

Matsuoka, K., Kobayashi, T., Ueno, F., Matsui, T., Hirai, F., Inoue, N., Kato, J., Kobayashi, K., Kobayashi, K., Koganei, K., Kunisaki, R., Motoya, S., Nagahori, M., Nakase, H., Omata, F., et al. (2018) Evidence-based clinical practice guidelines for inflammatory bowel disease. J. Gastroenterol., 53, 305-353.

Molinie, F., Gower-Rousseau, C., Yzet, T., Merle, V., Grandbastien, B., Marti, R., Lerebours, E., Dupas, J.L., Colombel, J.F., Salomez, J.L. \& Cortot, A. (2004) Opposite evolution in incidence of Crohn's disease and ulcerative colitis in Northern France (1988-1999). Gut, 53, 843-848.

Murakami, Y., Nishiwaki, Y., Oba, M.S., Asakura, K., Ohfuji, S., Fukushima, W., Suzuki, Y. \& Nakamura, Y. (2019) Estimated prevalence of ulcerative colitis and Crohn's disease in Japan in 2014: an analysis of a nationwide survey. J. Gastroenterol., 54, 1070-1077.

Ng, S.C., Shi, H.Y., Hamidi, N., Underwood, F.E., Tang, W., Benchimol, E.I., Panaccione, R., Ghosh, S., Wu, J.C.Y., Chan, F.K.L., Sung, J.J.Y. \& Kaplan, G.G. (2017) Worldwide incidence and prevalence of inflammatory bowel disease in the 21 st century: a systematic review of population-based studies. Lancet, 390, 2769-2778.

Nguyen, G.C., Sheng, L. \& Benchimol, E.I. (2015) Health care utilization in elderly onset inflammatory bowel disease: a population-based study. Inflamm. Bowel Dis., 21, 777-782.

Nicholls, R.J., Clark, D.N., Kelso, L., Crowe, A.M., Knight, A.D., Hodgkins, P. \& Satsangi, J. (2010) Nationwide linkage analysis in Scotland implicates age as the critical overall determinant of mortality in ulcerative colitis. Aliment. Pharmacol. Ther., 31, 1310-1321.

Sato, H., Yokomichi, H., Takahashi, K., Tominaga, K., Mizusawa,
T., Kimura, N., Kawata, Y. \& Terai, S. (2019) Epidemiological analysis of achalasia in Japan using a large-scale claims database. J. Gastroenterol., 54, 621-627.

Shi, H.Y., Chan, F.K., Leung, W.K., Li, M.K., Leung, C.M., Sze, S.F., Ching, J.Y., Lo, F.H., Tsang, S.W., Shan, E.H., Mak, L.Y., Lam, B.C., Hui, A.J., Wong, S.H., Wong, M.T., et al. (2016) Natural history of elderly-onset ulcerative colitis: results from a territory-wide inflammatory bowel disease registry. $J$. Crohns Colitis, 10, 176-185.

Shivananda, S., Lennard-Jones, J., Logan, R., Fear, N., Price, A., Carpenter, L. \& van Blankenstein, M. (1996) Incidence of inflammatory bowel disease across Europe: is there a difference between north and south? Results of the European Collaborative Study on Inflammatory Bowel Disease (EC-IBD). Gut, 39, 690-697.

Song, E.M., Lee, H.S., Park, S.H., Kim, G.U., Seo, M., Hwang, S.W., Yang, D.H., Kim, K.J., Byeon, J.S., Myung, S.J., Yang, S.K. \& Ye, B.D. (2018) Clinical characteristics and long-term prognosis of elderly onset ulcerative colitis. J. Gastroenterol. Hepatol., 33, 172-179.

Stallmach, A., Hagel, S., Gharbi, A., Settmacher, U., Hartmann, M., Schmidt, C. \& Bruns, T. (2011) Medical and surgical therapy of inflammatory bowel disease in the elderly - prospects and complications. J. Crohns Colitis, 5, 177-188.

Statistics Bureau of Japan (2020) Statistical Handbook of Japan 2020. https://www.stat.go.jp/English/data/handbook/index.html [Accessed: May 31, 2021] (in Japanese).

Takahashi, H., Matsui, T., Hisabe, T., Hirai, F., Takatsu, N., Tsurumi, K., Kanemitsu, T., Sato, Y., Kinjyo, K., Yano, Y., Takaki, Y., Nagahama, T., Yao, K. \& Washio, M. (2014) Second peak in the distribution of age at onset of ulcerative colitis in relation to smoking cessation. J. Gastroenterol. Hepatol., 29, 1603-1608.

Taleban, S., Colombel, J.F., Mohler, M.J. \& Fain, M.J. (2015) Inflammatory bowel disease and the elderly: a review. $J$. Crohns Colitis, 9, 507-515.

Toruner, M., Loftus, E.V. Jr., Harmsen, W.S., Zinsmeister, A.R., Orenstein, R., Sandborn, W.J., Colombel, J.F. \& Egan, L.J. (2008) Risk factors for opportunistic infections in patients with inflammatory bowel disease. Gastroenterology, 134, 929-936.

Turner, D., Walsh, C.M., Benchimol, E.I., Mann, E.H., Thomas, K.E., Chow, C., McLernon, R.A., Walters, T.D., Swales, J, Steinhart, A.H. \& Griffiths, A.M. (2008) Severe paediatric ulcerative colitis: incidence, outcomes and optimal timing for second-line therapy. Gut, 57, 331-338.

Ungaro, R., Mehandru, S., Allen, P.B., Peyrin-Biroulet, L. \& Colombel, J.F. (2017) Ulcerative colitis. Lancet, 389, 17561770 .

Van Limbergen, J., Russell, R.K., Drummond, H.E., Aldhous, M.C., Round, N.K., Nimmo, E.R., Smith, L., Gillett, P.M., McGrogan, P., Weaver, L.T., Bisset, W.M., Mahdi, G., Arnott, I.D., Satsangi, J. \& Wilson, D.C. (2008) Definition of phenotypic characteristics of childhood-onset inflammatory bowel disease. Gastroenterology, 135, 1114-1122. 